\title{
Zur Frage der Bäder- oder medikamentösen Behandlung des Unterleibstyphus.
}

Von Dr. J. Rembe in Ludwigshafen a. Rh.

Mit allergrösstem Interesse las ich in No. 16 der Deutschen medizinischen Wochenschrift 1903 den Aufsatz von Prof. Valentini (Danzig) über die antifebrile Behandlung des Typhus (mit Pyramidon). Diese Frage stand schon einmal, und zwar im Jahre 1884 und die folgenden Jahre zur Debatte, um, wie es anfänglich schien, ähnlich wie von Prof. Valentini entschieden zu werden. Sie verschwand aber dann von der Bildfläche und zwar, wie ich glaube, mit Unrecht.

Ich möchte zunächst noch einmal auf die Geschichte der antifebrilen Typhusbehandlung zurückkommen, weil letztere in obigem Aufsatze etwas kurz wegkam und ich es auch für gerechtfertigt halte, dass die damaligen Arbeiten etwas mehr berücksichtigt werden.

Nachdem das von Straup dargestellte Thallin von Jaksch 1884 zuerst in die Therapie eingeführt wurde, haben, ausser anderen Autoren, besonders die Professoren P. Ehrlich und B. Laquer dasselbe beim Typhus in Anwendung gezogen (siehe No. 51 der Berliner klinischen Wochenschrift 1885).

Dieselben haben es anfänglich sehr günstig beurtheilt, haben es aber später wieder fallen lassen, wegen seiner angeblichen Schädigung des Herzens und ungünstigen Wirkung auf die Blutkörperchen. Versuche mit anderen Antifebrilien haben aber weitaus nicht die günstige Wirkung ausgeübt und werden seither nur, wie Prof. Valentini ganz richtig hervorhebt, in vereinzelten Dosen angewendet, um die Temperatur voriibergehend herabzusetzen.

Im Jahre 1885 habe ich das Thallin zunächst an mir versucht und es von da ab, wo sich Gelegenheit bot, beim Typhus verwendet, wobei ich genau zu denselben (Beobachtungen) Resultaten kam, wie jetzt Prof. Valentini mit Pyramidon. Im Jahre 1896 (No. 80 der Deutschen Medizinalzeitung) habe ich meine Erfahrungen und Beobachtungen zusammengestellt und erwähnt, dass Prof. Demme und der damalige Assistent am Dresdener Krankenhause, Dr. Steffen, ebenfalls guinstige Erfahrungen mit der Thallinbehandlung des Typhus machten, aber die Sache war nicht mehr zu retten, jedenfalls habe ich in der Litteratur keine weiteren Angaben mehr darüber gefunden. Ich war und bin so sehr von der günstigen, oft gerade spezifischen Wirkung der Thallinwirkung überzeugt, dasss ich mir alle Mühe gab, Laboratoriumsversuche mit Typhusbazillen auf thallinisirten Nährboden zu veranlassen, um die Entwickelung und das Verhalten der Typhusbazillen zu studiren oder an infizirten Thieren durch Sektionsergebnisse den Einfluss des Thallins festzustellen, aber leider konnte ich meine Wünsche nicht in die Wirklichkeit umsetzen.

Wegen der Einzelheiten der Thallinbehandlung muss ich auf das Original verweisen. Hier möchte ich nur hervorheben, dass ich aus- 
drücklich betonte, dass es bei der Behandlıng durchaus darauf ankomme, bis zu der Dose zu steigen, die vollständige Fieberlosigkeit erzengt und dass man dabei bleibt, bis man hoffen kann, auch bei kleineren und in grösseren Zwischenräumen gegebenen Dosen keine Temperaturerhöhung mehr eintreten zu sehen.

Ueber das merkwürdige Verhalten des Allgemeinbefindens decken sich die Betrachtungen von Prof. Valentini und mir vollständig. Mir ist es wiederholt passirt, dass andere Collegen, denen ich solche Kranke zeigte, an der Diagnose zweifelten, bis sie durch den Nachweis der einzelnen Symptome und durch die entsprechende Fieberkurve beim Weglassen des Mittels eines besseren belehrt wurden.

Die antifebrile Behandlung des Typhus wirft ein sehr interessantes Streiflicht auf eine andere Frage, die noch sub lite steht, nämlich: Ist das Fieber eine Heilpotenz der Natur oder nicht? Wenn man sich der wichtigen Versuche, die Dozent Hertz in Wien mit infizirter Hefe anstellte nnd die leider viel $\mathrm{zu}$ wenig gewürdigt wurden, erinnert und bedenkt, dass gerade die Specifica wie Salicylsänre bei Gelenkrhenmatismus, Chinin bei Malaria zuerst das Fieber hermutersetzen, um dann die Krankheit zu beseitigen, wenn man weiter bedenkt, dass auch die Injektion der Heilsera ähnlich wirkt, so kann man meiner Ansicht nach nicht auf dem oppositionellen Standpunkte stehen bleiben und der energischen Fieberbehandlung ablehnend gegenüberstehen. Allerdings muss dieselbe mit Beachtung eventueller unangenehmer Nebenerscheinungen vor sich gehen.

Mag nun Thallin oder Pyramidon den Vorzug verdienen, jedenfalls schliesse ich mich voll und ganz dem Wunsche Valentini's an, dass die Anhänger der Bäderbehandlıng einmal einen Versuch mit dieser Behandlungsmethode machen möchten und ich bin fest überzengt, dass bei dem enragirtesten Wasserschwärmer bald eine Bekehrung eintreten wird wegen der grossen Vereinfachung der Behandling bei ungleich besserem Verlanfe der Krankheit. 